\title{
A Imagem Poética e Fotográfica de Sérgio de Castro Pinto
}

\author{
Maria Marta dos Santos Silva Nóbrega (UFCG)
}

RESUMO: A imagem câmera de Sérgio de Castro Pinto em O Cerco da memória apresenta-se dissonante e anormal quando busca espaços de representação de uma outra realidade. O poeta faz uso de uma linguagem diferente na Retórica modernista e para enfatizar sua atitude, assume o ofício de fotógrafo. Este trabalho objetiva compreender como o poeta se situa no centro da modernidade ao fixar, em sua obra, os postulados da era da técnica. Nessa poética, a máquina é um instrumento frio, metáfora do homem nessa era tecnicista, que na medida em que cresce em consciência própria, vai internalizando o mundo objetivo, mudando-o poeticamente.

PALAVRAS-CHAVE: Sérgio de Castro Pinto, imagem, poeta fotógrafo.

ABSTRACT: Sérgio de Castro Pinto's camera image in O Cerco da Memória (The Siege of Memory) appears dissonant and abnormal as it finds room for representing another reality. The poet uses a different language in his moderninst Rhetoric, and in order to highlight his attitude, he acts like a photographer. This work aims to understand how the poet places himself in the centre of modernity as he establishes, in his work, the postulates of the technical age. In this poetics, the machine is a cold instrument, man's metaphor in this technicist age. As it grows in its own conscience, it keeps on internalizing the objective world and changing it poetically.

KEYWORDS: Prose poem; Lyrical poetry; Modernity; Modern literature.

Neste trabalho pretendemos comentar alguns aspectos estéticos da modernidade lírica utilizados por Sérgio de Castro Pinto em O Cerco da memória (2006) - livro que reúne poemas selecionados do livro homônimo publicado em 1993, de Gestos lúcido (1967), de A Ilha na ostra (1970) e de Domicílio em trânsito (1993). Para as reflexões dobre lirismo moderno, nosso apoio teórico será Benjamim (1983) e Friedrich (1991).

$\mathrm{Na}$ estética modernista vista por Walter Benjamim há, pelo menos, duas categorias centrais responsáveis por um novo conceito de autenticidade para a arte: a destruição da aura e a reabilitação da alegoria. Essas duas categorias estão ligadas aos fenômenos da reprodução mecânica e da perda da experiência. 
Os postulados benjaminianos quando aplicados aos estudos sobre fotografia, cinema, poesia de Baudelaire, ficção de Proust e outras modalidades do campo artístico anulam a eficácia mimética da arte. Para Benjamim, o novo da arte é revelado pela sua força de produção. Ao mesmo tempo em que a obra de arte se adapta ao público com o uso das facilidades técnicas, também desafia a este mesmo público visto apresentar um conteúdo pouco acessível, como é o caso de muitos poemas de Sérgio de Castro Pinto, a exemplo de "atos falhos", transcrito a seguir:

Atos falhos

sequer os ensaio.

mas os meus atos

falhos

encenam-se assim:

eles já no palco

e eu ainda

no camarim.

O poema expressa uma consciência de que no contexto da modernidade - em que predomina o paradoxo, "uma unidade de desunidade" (Berman, 1986:15) -, homem, realidade e linguagem não se encontram pacificamente no horizonte da representação. Em meio à proliferação de signos, a linguagem falhou.

Essa perda de uma perspectiva integralizadora da existência, essa crise de cisão entre homem e mundo, na concepção de Alfredo Bosi (1993:142), se dá por vários motivos, entre eles, está "a extrema divisão do trabalho manual e intelectual, a ciência e, mais do que esta, os discursos ideológicos e as faixas domésticas do senso comum[...]." Como sintoma desse estado de consciência, o esforço expressivo que cada poeta empreende figurará os contornos de uma negação própria, identificadora, refletida em cada imagem criada. O poeta moderno consciente de sua condição diante da sociedade, 
transforma sua expressão numa espécie de campo dilacerado para onde converge o descompasso que raia a existência cotidiana. O poeta, conforme Bosi (1993:151), tornase "demiurgo da própria existência, tenta abrir no espaço do imaginário uma saída possível". Não obstante as inquietações do mundo moderno, a poesia preserva sua natureza original, criativa, evocadora de essências simbólicas no plano do ser.

A imagem de "atos falhos", constitui-se instância fundadora na percepção de Castro Pinto e não uma mera representação de um ser específico. Fundado num ritmo existencial ("eles já no palco e eu ainda no camarim"), o poema sugere um processo reiterativo, fotograficamente, que reproduz uma realidade fugidia e incorpora uma consciência acusativa que tende a desqualificar e a esvaziar o sentido de ser do poeta.

A partir desta perspectiva, vemos que, na modernidade, não há destruição da aura como queria Benjamim. Há sim, um novo tipo de sagração motivada pela imediatez da técnica que leva o homem a produzir algo que ultrapassa o cotidiano. Neste novo estado de criação, o poeta já não tem consciência acerca de si. E essa é uma marca forte da modernidade: a descoberta dos limites existenciais do homem em que a existência é concebida como ficção, conforme sugere a última estrofe de "atos falhos". O mesmo se pode ver no poema transcrito abaixo:

poeta $\mathrm{x}$ poema

nem sempre o poeta

ronda o poema como uma fera a presa.

às vezes, fera presa e acuada

entre as grades do poema-jaula,

doma-o o chicote das palavras.

Considerando que o ato criador é um processo, sua primeira dimensão implica na imprevisibilidade. O poema tem o tom de uma profissão de fé marcada pela aventura de quem mesmo, sabendo da necessidade de um preparo cuidadoso para uma jornada 
poética a fim de dar essência ao poema, não sabe, o poeta, o caminho no qual é lançado, posto que, vê-se desafiado pelo próprio poema. O poema, antes dependente do poeta, agora apresenta-se autônomo, incomoda o poeta ao ponto de chicoteá-lo as palavras. $\mathrm{O}$ poema ressalta a possibilidade de, partindo das diferenças entre produtor (poeta) e produto (poema), se pode chegar a um jogo dialético onde não haverá um afastamento, mas uma agregação de um no outro, de forma que se perceba como o "outro, o longínquo é também o mais próximo e o mesmo" (Foucault, 1992:320).

Já no poema "escrever/não escrever" o aspecto de fabricação da realidade se percebe na intelectualização da sensibilidade e na reflexão crítica reforçada pelo conteúdo metalingüístico do texto que perpassa o poema:

Escrever/não escrever

escrever é um suicídio branco.

um consumir-se no fogo brando das palavras.

não escrever, um suicídio em branco

um consumar-se sem metáforas.

Ao considerarmos a atitude poética de Castro Pinto semelhante a de um fotográfico que prima pela "estandalização" temporal, há de se considerar que as sensações de limitação e finitude vivenciadas pelo poeta fortalecem seu impulso fotográfico para aglutinar momentos passados, presentes e futuros no interior do poema. Neste sentido, o tempo, na poética em questão, quando é tomado como elemento poético, não é tomado precipitadamente. Ao contrário, sua elaboração lenta, gradativa, meticulosa através de outros elementos ligados a ele, vai se casar perfeitamente com o olhar câmera que move o poeta, de início a fim, e lhe oferece uma oportunidade de fugir, pela abstração da revelação, da natureza fechada, asfixiante que o cerca. No poema "o homem revela a memória da máquina" é perceptível essa performance poética.

O homem revela a memória da máquina 
Da máquina

O homem revela a memória

E o que estava dentro

Revela-se ao lado de fora.

Da máquina

Pululam crinaças, peixes,

Sorrisos, elefantes...

E tornar-se coisificado

O que era abstrato antes.

Da máquina, no laboratório (escuro),

Pulam manhãs

E dóceis se misturam

Crianças, tigres e rãs.

Há, neste poema, uma determinação em registrar o momento presente. A "memória" que o "homem revela" se temporaliza ao ganhar movimento, ritmo próprio. O impulso do movimento opera a fusão entre tempo e espaço. Daí a consistência de elementos contrários: "dentro"/"fora", "coisificado"/"abstrato" que revelam o desejo de transpor um novo espaço-tempo definido. Na revelação da máquina é a essência viva da realidade (crianças, peixes, sorrisos) que permanece apesar de todas as transformações propiciadas no escuro do laboratório que conjugou harmonicamente num mesmo tempo-espaço "crianças, tigres e rãs".

Em outro poema "o homem conduzindo a máquina de fotografar", face à brevidade da vida, o poeta realiza uma abertura de possibilidades para o ser tornar-se apto à congelar instantes:

na máquina 
a paisagem é intestina

(o fora está dentro),

não pode mostrar-se ainda.

a máquina

guarda o que havia fora

e o homem a conduzindo

conduz duas memórias:

uma a da máquina (mais dentro)

e a outra a do homem (mais fora).

A valorização do instante flagrado pelas lentes da máquina é o trampolim para o aspecto atemporal sugerido na poética do autor. A presença dos verbos no presente, com exceção de "havia", coloca o poeta na posição demiurga de um fotógrafo. Trata-se de uma miragem que contém todo o potencial da existência de dois planos: o da máquina e o humano.

A partir deste rápido olhar na poética de Sergio de Castro Pinto, pode-se inferir que a produção poética do autor se insere no contexto da lírica moderna, no que ela tem de dissonante, anormal e obscura. Para Hugo Friedrich (1991), a negatividade da lírica moderna é marcada pela obscuridade que fascina e desconcerta, simultaneamente, e tem seus fundamentos na "dissonância e anormalidade" que atravessam o imaginário poético contemporâneo e cujas implicações são particulares a cada autor. A dissonância caracteriza-se pela "junção de incompreensibilidade e de fascinação, [...] pois gera uma tensão que tende mais à inquietude que à serenidade". A dissonância, pois, acaba por favorecer uma obscuridade intencional em confronto com a objetividade percebida nas relações sociais.

A anormalidade mobiliza no espaço poético um efeito de surpresa e de estanhamento tanto no leitor quanto no próprio poeta, para quem o "conhecimento do sentido daquilo que compôs é limitado". Embora seja um conceito complexo, posto que 
"suscita a impressão de que existe uma norma sempiterna", ao mesmo tempo, serve para confrontar as mudanças sensíveis ao longo da sucessão dos movimentos literários. Assim, para que a inquietação conquiste certo grau de expressividade, o poeta abeira-se das imagens e dos sentimentos "anormais". Dissonância e anormalidade configuram-se, pois, em opções poéticas que reforçam o contínuo mal-estar do ser poético com a sociedade.

Um terceiro elemento que caracteriza a obscuridade da lírica moderna é a acidentalidade, de onde emana a figura do transitório, idéia de temporalidade que bem se ajusta à vivência do que se propõe dissonante e anormal. Transitória e acidentada é a relação estabelecida entre o poeta e os fragmentos da realidade que ele próprio nomeia, mesmo que esteja em jogo o conflito de forças absolutas representantes do confronto do eu com a objetividade circundante. Isto posto, a obscuridade da lírica moderna coloca em evidência um sentimento do mundo marcado pelo negativo que acaba por engendrar as mais diversas identidades para a expressão poética.

Esses três elementos da lírica moderna quando relacionados à poética de Castro Pinto ainda que propiciem revelar um espetáculo de imagens representativas de um flagrante poético, deixam como rastro final a negação do sujeito. Nos poemas citados há uma série de evidências que reforçam a sensibilidade do poema e apontam para uma confluência entre o movimento das imagens e a atitude fotográfica do poeta. Enquanto poética representativa da era técnica, a produção de Castro Pinto expõe tanto a dramática consciência da condição humana em meio às formas desgastadas da vida moderna quanto revela a necessidade de congelar alguns instantes, mesmos que fugidios desta mesma condição. Dessa forma, transparecem as fraturas nas imagens do mundo e nas imagens do ser, a marca da perda, da falta de referências básicas do ser humano diante dos valores ditados pelas ideologias dominantes. Nessa crise de representatividade, Castro Pinto constrói sua poética fotográfica congelando imagens fugidias, buscando, assim, nessa atitude tecnicista recuperar o sentido da poesia. 


\section{REFERÊNCIAS}

BENJAMIM, Walter. A obra de arte na época de suas técnicas de reprodução. In: Textos Escolhidos. Trad. De José Lino Grünnewald... et al. $2^{\mathrm{a}}$ ed. São Paulo: Abril Cultural, 1983.

BERMAN, Marshal. Tudo que é sólido desmancha no ar. São Paulo: Companhia das Letras, 1986.

BOSI, Alfredo. O ser o tempo na poesia. São Paulo; Cultrix, 1993

FOUCAULT, Michel. As palavras e as coisas. São Paulo: Martins Fontes, 1992.

FRIEDRICH, Hugo. Estrutura da lírica moderna. São Paulo: Duas cidades, 1991.

PINTO, Sérgio de Castro. O cerco da memória. $2^{\text {a }}$ ed. João Pessoa: Editora Universitária/UFPB, 2006. 